\title{
Arteztutako gainazaletan diamantatze prozesuko patroiak karakterizatzeko metodologiaren garapena
}

\section{A novel development for characterizing dressing helical patterns on ground parts surfaces}

\author{
Aitzol Galletebeitia*1, Gorka Uranga ${ }^{1}$, Jorge Álvarez ${ }^{1}$, Íñigo Pombo ${ }^{2}$ \\ ${ }^{1}$ IK4-IDEKO S. Coop. Fabrikazio Prozesuen ikerketa lerroa \\ ${ }^{2} \mathrm{UPV} / \mathrm{EHU}$
}

\begin{abstract}
LABURPENA: Diamantatze prozesuaren eragin nabarmenetako bat da prozesuak pieza arteztuaren gainazalaren akabera baldintzatzen duela. Hain zuzen, aitzinapen transbertsaldun diamantatze prozesuen eraginez, arteztutako piezen gainazalean helize itxurako markak agertu ohi dira. Gisa horretako markak agertzeak eragin kaltegarriak izan ditzake zenbait aplikazioren errendimenduan, piezen funtzio nagusia zigilatzea edo koipeztatzea bada. Horren aplikazio nabarmenetako bat zigilu erradialak daramatzaten ardatz birakariak dira, non ezinbestekoa gertatzen den zigiluaren bizitza ahalik eta gehien luzatzea betiere zigilatzea bermatuaz. Horretarako, ezinbestekoa gertatzen da piezaren gainazala neurtu eta helize itxurako patroiak era egoki batean karakterizatzea. Artikulu honetan, patroi horiek ebaluatzeko erabiltzen diren ohiko metodoen berrikusketa sakon bat egiteaz gain, metodologia berri baten berri emango da, IK4-Ideko garatzen ari dena arteztutako gainazalak neurtzeko eta dressing-leada karakterizatzeko.
\end{abstract}

HITZ GAKOAK: dressing-lead, patroi helikoidalak, diamantatze, artezketa, azal akabera, zigilu erradial.

ABSTRACT: One of the most influential effects of the dressing process is that this process conditions the surface finish of the final part. In fact, due to the transversal dressing process, some periodical helical patterns appear on the surface of the ground parts. The presence of these marks can lead to a negative impact on the performance of certain sealing applications. One of the most outstanding applications are the rotating shafts where the radial seals are mounted, where it is essential to guarantee sealing performance and extend the seal life as long as possible. To do this, it is essential to measure the surface of the ground part and to characterize its helical patterns appropriately. In this article, in addition to a thorough review of the usual methods currently used, the measurement of surfaced surfaces and a methodology for the characterization of dressing-lead developing at IK4-Ideko will be reported.

KEYWORDS: dressing-lead, dressing, grinding, surface finish, helical patterns, radial seals.

\footnotetext{
* Harremanetan jartzeko / Corresponding author: Aitzol Galletebeitia. - agalletebeitia@ideko.es - https://orcid.org/

Nola aipatu / How to cite: Galletebeitia, Aitzol; Uranga, Gorka; Álvarez, Jorge; Pombo, íñigo (2019). «Arteztutako gainazaletan diamantatze prozesuko patroiak karakterizatzeko metodologiaren garapena»; Ekaia, ale berezia 2019, 85-99. (https://doi.org /10.1387/ekaia.19862).

Jasoa: 1 ekaina, 2018; Onartua: 4 iraila, 2018.
}

ISSN 0214-9001 - eISSN 2444-3255 / (c) 2019 UPV/EHU

(c) (i) (2) Obra hau Creative Commons Atribución 4.0 Internacional-en

BY No sA $_{\text {a }}$ lizentziapean dago 


\section{SARRERA}

Grinding is dressing esaldia ohikoa da artezketaren munduan dabilenarentzat [1]. Esaldi horren esanahia zera da: diamantatze prozesuak ondorengo artezketa operazioan eragin nabarmena izango duela. Artezte prozesuetan, denboraren poderioz harriaren gainazala higatuz joan ohi da, azken horren ebaketa-ahalmena gutxituaz. Diamantaketa operazioaren helburu nagusia artezteko harriaren ebaketa-ahalmena puntu optimoan berrezartzea da, artezteko harriaren higadura minimizatuaz eta piezaren bukaerako kalitatea bermatuaz uneoro. Harri urratzailearen topografia eraldatzeko gaitasuna dela medio, diamantaketa operazioak eragin nabarmenak izan ditzake material harroketa tasan, artezketa operazioko indarretan, piezaren akaberako kalitatean edo artezteko harriaren higaduran.

Industrian hedatutako aplikazio gehienetan, diamantezko erraminta batekin artezte harriaren gainazala mekanizatzean datza prozesua, eta hortik datorkio izena. Operazio honen helburua harriaren topografia eraldatzea da; ebaketa-ahalmena galdu duten ale urratzaileak harriaren gainazaletik erauziaz eta ale berri eta zorrotzak bistaratuaz, edota harrian gainazalean itsatsitako txirbilak harrotuaz. Artikulu honetan, diamantatze prozesuari buruz hitz egiten dugunean, era honetako diamantaketa operazioei buruz ariko gara.
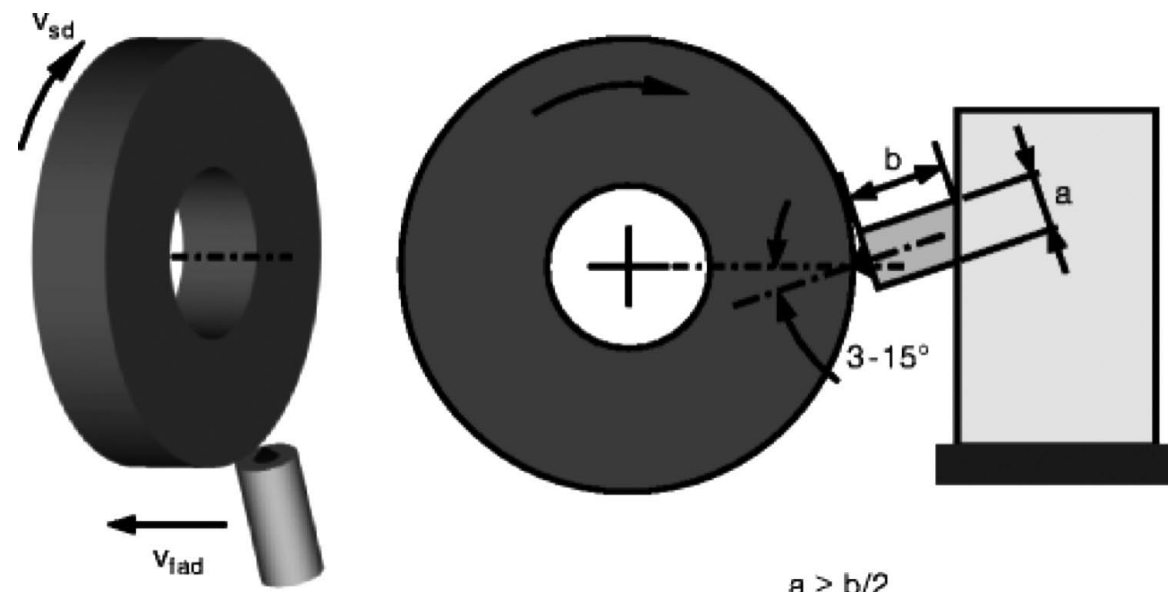

$a \geq b / 2$

1. irudia. Aitzinapen transbertsaldun diamantaketa operazioaren zinematika [2].

Diamantaketa operazioen artean, sarrien erabiltzen direnen artean dago aitzinapen transbertsaldun diamantaketa operazioa. Era honetako prozesuetan, diamantezko erraminta bat harri urratzailearen periferiatik higitzen da 
harriaren norabide axialari jarraituaz (1. irudia). Horren ondorioz, harriaren gainazalean espiral itxurako patroi bat sortzen da, zeina, artezte operazioko parametro teknologikoen arabera, era batean edo bestean arteztutako piezaren gainean kopiatuko den.

Helize itxurako gainazal hau kaltegarria izan daiteke estankotasuna bermatu behar duten zigilu erradialak daramatzaten hainbat aplikaziotan. Zigiluok ardatz birakari arteztuen soinean muntatuta joan ohi dira. Ardatz horien gainazalen akaberak zigiluaren erabilera bizitza, horrek jasango duen higadura eta zigilatze errendimendua baldintzatuko ditu. Horregatik, industrian ezinbestekoa gertatzen da arteztutako piezen gainazaletan agertzen diren mota honetako markak neurtuko dituzten eta egokiro karakterizatuko dituzten metodologiak garatzea.

\section{ZIGILU ERRADIALAK}

\subsection{Zer da leada?}

Zigilatze teknologiaren alorrean, lead izenez ezagutzen dira ardatzaren gainazalean agertzen diren markak, zeinek, ardatzaren biraketa abiaduraren eraginez, norabide axialean fluido baten ihesa eragin dezaketen zigiluaren eta ardatzaren arteko aurpegian zehar [3].

Zigilatze aplikazioetan erabiliko diren ardatzen kasuan mota bitako helize itxurako testurak bereizten dira: macro-leada eta micro-leada [4]. Lehendabizikoak ardatzaren periferia osoan agertzen diren marka helikoidal periodiko eta jarraituak dira. Bigarren motako testura, aldiz, gainazalean agertzen diren marka isolatuengatik da ezaguna, zeinek punpatze efektu bat sor dezaketen zigilatze gaitasunean eragin negatiboa izango duena (ikus 2. irudia).

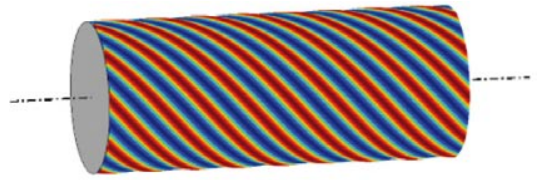

(a) Macro lead

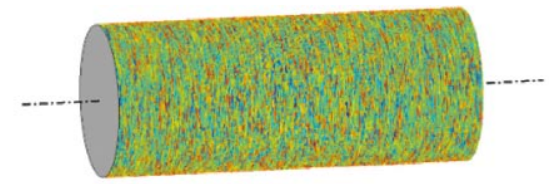

(b) Micro lead

2. irudia. Patroi helikoidalen bereizketa [4].

Autore batzuen arabera [4-5], aitzinapen axialdun diamantatze prozesuaren ondorioz, harri urratzailearen gainazalean helize itxurako markak sortuko dira, eta era berean, piezan markak agertu daitezke, artezketa operazioko parametroen arabera eta harriaren eta piezaren arteko lerrokatzearen arabera. 


\subsection{Zigilu erradial dinamikoen funtzionamendua}

Zigilu erradial bat sistema konplexu bat da, «zigilatze elementu» bakar batetik harago doana eta zigilatze estatiko zein dinamikoa helburu daukaten hainbat elementuk osatua. Zigilu erradial dinamiko baten kasuan, ardatz birakari batek, zigilatze elementu batek, zigilatu beharreko fluidoak eta operazioko zein inguruneko baldintzek definituko dituzte sistema konplexu hau osatuko duten elementuak (ikus 3. irudia).

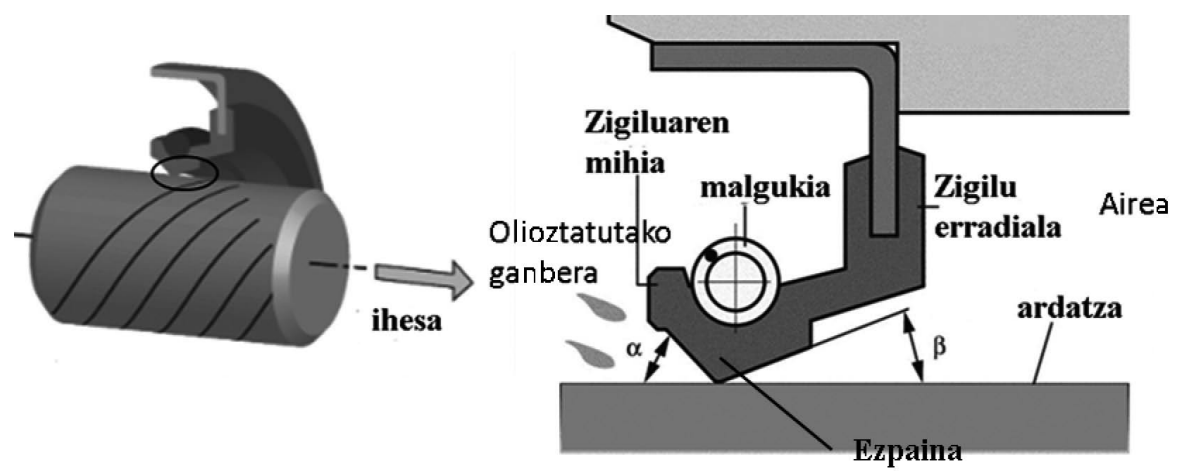

3. irudia. Zigilu erradial dinamiko baten elementuak [5].

Operazio baldintzetan, ardatz birakari bat abiadura jakin batean biraka ariko da haren inguruan zigilu erradial elastiko bat duelarik. Zigilatze elementuak ardatzari presio edo karga erradial jakin bat eragingo dio kontaktu luzera deritzon zabaleran zehar, mihia deritzon elementuaren bitartez, zigilatze estatiko zein dinamikoa bermatu nahian.

Ardatza egoera geldikorrean dagoenean, zigiluaren karga erradialak bermatuko du isolatze efektua, zigiluak daraman malgukiari esker. Aldiz, ardatza biraka ari denean marruskadura egoera misto bat gertatzen da, non, indar zentrifugoaren eraginez, zigiluaren mihia ardatzaren gainazaletik bereizi eta agente lubrifikatzaileak higitzeko erraztasuna duen. Egoera horretan, ardatz birakariaren gainazaleko mikroestrukturek punpatze-gaitasuna daukate. Zigiluek bermatu beharko dute agente lubrifikatzailearen ihesik ez dela gertatuko nahiz eta punpatze efektu hori agertu.

Era berean, kontaktuko gainazalen artean nahikoa lubrifikatzaile dagoela bermatu behar da, zigiluaren lehorreko funtzionamendurik gertatzen ez dela bermatzeko. Azken hori gertatuz gero, zigiluko mihiaren higadura nabarmen igo, eta haren erabilera bizitza nabarmen laburtuko da.

Hala ere, industriak jasan duen espezializazio eta globalizazio orokorraren eraginez, kasu gehienetan agente lubrifikatzaileen aukeraketa eta zigiluaren diseinua hornitzaileen esku geratzen dira, eta ardatz birakarien fabrikazioa, 
aldiz, ekoizle nagusiaren ardura izaten da. Zigilatze multzoen fabrikazioaren zati baten azpikontratazioak multzo osoaren kalitate kontrola zailtzen du, eta, beraz, produkzio kostuak merkatzeko ahalegin gehienak ardatzaren fabrikazioan eta horren gainazalaren akaberaren kontrolean zentratzen dira.

Hori dela eta, ekoizle nagusiak argi izan behar du zein den zigilatzearekin lortu gura duen helburu nagusia. Horri dagokionez, zigiluen bi funtzionamendu printzipio bereiz ditzakegu:

- Lubrifikatutako ganberaren edo espazioaren zigilatzea.

- Kanpoaldeko agente edo partikula kutsagarrietatik isolatzea.

\subsection{Zigilu erradialen kalitate kontrola}

Zigilatze aplikazioetako ardatz birakariek hainbat eskakizun bete behar dituzte, haien estankotasuna bermatuko bada. Kasu askotan, azken bezeroak ezarriko ditu eskakizun horiek, baina 2007az geroztik indarrean dagoen ISO 6194-1:2007 [6] estandarrari jarraitzen diote gehienek, bertan definitzen baitira zigilatze ardatzen tolerantzia geometrikoak. Ondorengo lerroetan ekoizle nagusien aburuz (SKF, Freudengberg, Parker...) zigilatzea bermatu ahal izateko gainazalen akaberak bete behar duen eskakizun nagusietako bat laburbiltzen da: no-lead surface condition.

Automobilgintzako aplikazio askoren kasuan, zigiluak bi funtzionamendu printzipio bete beharko ditu: batetik, agente lubrifikatzearen ihesa ekiditea; bestetik, kanpoaldeko agente edo partikuletatik babestea. Printzipio horiek biak bete behar dituzten zigiluetako ardatzen gainazalek patroi helikoidalik gabeko egoera edo no-lead condition deritzon egoera bete beharko dute.

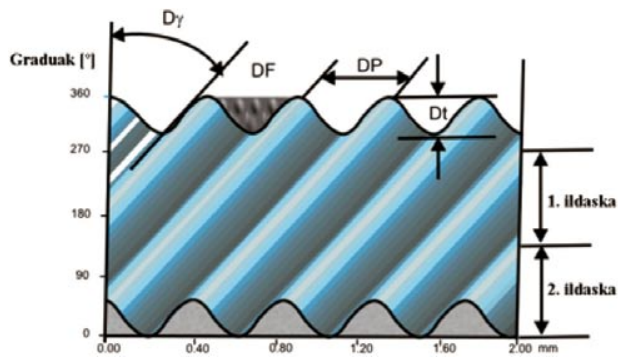

\begin{tabular}{cl}
\hline Nomenklatura & Deskripzioa \\
\hline Dy $[\mathrm{Q}]$ & Testuraren orientazioa \\
Dt $[\mu \mathrm{m}]$ & Ildasken sakonera \\
DP $[\mathrm{mm}]$ & $\begin{array}{l}\text { Norabide axialeko ildasken } \\
\text { arteko periodoa }\end{array}$ \\
DN & Periferiako ilsdaska kopurua \\
DF $[\mu \mathrm{m} 2]$ & Punpatze azalera aktiboa \\
\hline
\end{tabular}

4. irudia. Macro-leada ebaluatzeko parametrorik esanguratsuenak [8].

4. irudian erakusten dira, RMA OS-1-1 2004 estandarraren arabera, macro-leada deskribatzen duten parametrorik esanguratsuenak [8]. Nabarmendu beharreko efektua da testuraren noranzkoaren inklinazioa areagotu ahala $\left(\mathrm{D}_{\gamma}\right)$ sakonera handiagoko uhinak agertzeak $(\mathrm{Dt})$, uhin kopurua handi- 
tzeak (DN) edo punpatze azalera aktiboa (DF) handiagoa izateak ardatzaren eta zigiluaren arteko gainazalaren zigilatze gaitasuna txikiagotuko duela.

Arteztutako gainazaletan patroi helikoidalik dagoen ala ez ebaluatzeko ez da aski 2D-ko ohiko profilen neurketa. Era horretako neurketek zimurtasun parametroen $\left(R_{a}, R_{z}, R_{\max }\right)$ edo biribiltasun faltaren berri eman dezakete.

Horregatik, gainazaleko testuraren noranzkoaren ebaluazioa egin ahal izateko, neurketa metodologia konplexuagoak garatu behar dira, 3. atalean sakonduko denez.

\subsubsection{Fabrikazio prozesuko gomendioak}

Gainazaleko testura helikoidalen efektu hori erabat ezabatze aldera, ekoizle nagusiek plunge erako artezketa gomendatzen dute, diamantaketa oso fin bat eginaz, harriaren eta piezaren arteko biraketa abiadurako erlazio ez-osoak erabiliz eta txinparta akaberako denbora nabarmenak erabiliaz (20-30 s) [9]. Gisa horretako txinparta akaberako denbora luzeak gehiegizkoak izan daitezke masa-produkzioko piezen kasuan, non ekoizpen denbora faktore kritiko bihurtzen den.

Hala, ekoizpen denbora gutxitze aldera, eta punpatze efektuaren eraginak karakterizatzeko helburuarekin, gainazaleko testura neurtzeko hainbat metodo erabiltzen dira industrian. Hurrengo atalean, industrian hedatutako sistemarik nabarmenen berrikusketa teknikoa egingo da.

\section{NEURKETA SISTEMAK}

\section{1. «Hariaren» metodoa}

Metodo hau industrian erabiltzen den metodo zaharrena eta hedatuenetako bat da, ekoizle askok fabrikazio prozesuaren homologatze fasean erabiltzen baitute. Kasu honetan, ardatza horizontalki jartzen da euste baraila birakari batean, ardatzak masa bat zintzilik daukala hari baten bitartez (5. irudia). Arteztutako ardatzaren gainazaleko testurak noranzko jakin bat baldin badauka, haria norabide axialean mugituko da ardatza biratzen den heinean.

Patroi helikoidalak daudenean, hariaren mugimendua norabide batean edo bestean berdina izango da, ardatzaren biraketa noranzkoaren arabera. Metodo honen bitartez, micro-leadaren zein macro-leadaren noranzkoa era kuantitatibo batean azter daiteke (1. ek.).

$$
\text { Lead_Angle }[\mathrm{deg}]=\tan ^{-1}\left(\frac{\text { Hariaren aitzinapena }[\mathrm{mm}]}{\emptyset_{\text {ardatza }}[\mathrm{mm}] * R P M_{\text {ardatza }}\left[\frac{\mathrm{rev}}{\mathrm{min}}\right] * t[\mathrm{~min}]}\right)
$$




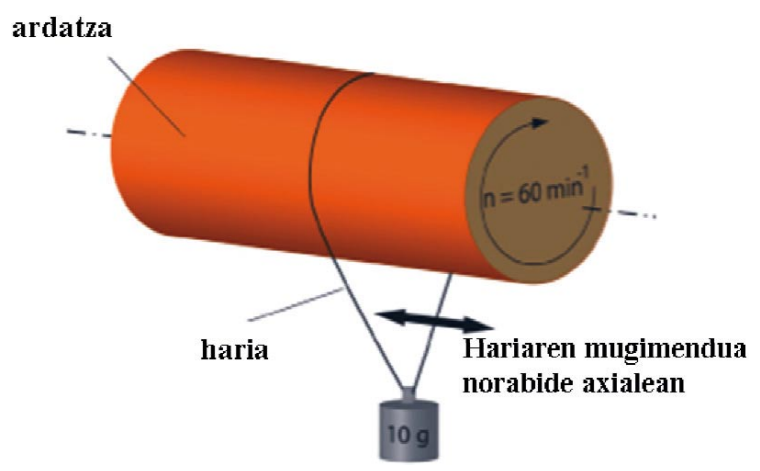

5. irudia. Hariaren metodoaren konfigurazioa [9].

Hala ere, ekoizle bakoitzak bere parametro propioak zehazten ditu saioak egiteko orduan (hari mota, zintzilik dagoen masaren pisua, gainazalaren lubrifikazio egoera edo ardatzaren biraketa abiadura). Aldakortasun horrek eta saioak egiteko pertsonalaren abileziak dudan jar ditzakete metodo honen objektibotasuna.

\section{2. «Argiaren dispertsioaren» metodoa}

Metodo hau Alemaniako Illmenau Unibertsitateko ikertzaileek garatu zuten [10]. Neurketa metodologia honen bitartez, ardatzaren gainazalean testura periodikoak agertzen diren ala ez ondoriozta daiteke era kualitatibo batean.

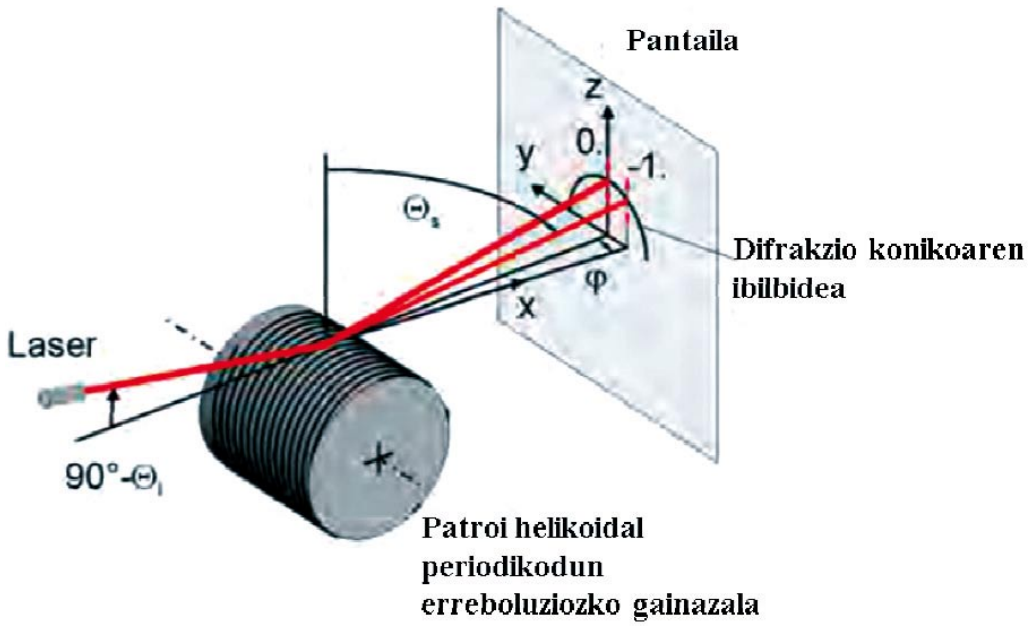

6. irudia. Gainazaleko egitura errepikakorrak azaleratzeko argiaren dispertsioaren metodoa [10]. 
Neurketa sistema honen funtsa argi izpi batekin ardatzaren gainazalari erasotzean datza. Orduan, argiak dispertsio bat jasango du, ezberdina piezaren zimurtasunaren arabera. DRAVI izeneko sentsorea gai izango da argi izpi horien dispertsioa neurtzeko eta era kualitatibo batean arteztutako piezaren gainazaleko patroi helikoidalaren sakonera eta luzera zenbatesteko.

Metodo honen abantaila nagusiak makinan bertan neurtzeko aukera eta haren neurtze denbora laburra dira. Aldiz, soilik era kualitatibo batean ebalua ditzake piezak, aurre-kalibrazio fase bat beharrezkoa izaki pieza mota bakoitzarentzat. Gainera, ez da gai gainazaleko testuraren ezaugarriak era numeriko batean kuantifikatzeko.

\section{3. «CARMEN» edo ordenagailuz lagundutako zimurtasunaren neurketa eta ebaluazio metodoa}

Hiru dimentsioko neurketa sistema hau Daimler-ek garatutako metodologia bat da [11]. Gainera, gainazaleko testurak era kuantitatibo batean neurtzeko metodologia honekin batera, estandarizazioko arau bat ezarri zuen: MBN 31 007-7. Arau hori azken hamarkadan industrian nabarmen hedatuz joan da, eta arau internazional batean barneratu du ISO erakundeak (DIN EN ISO 25178).

Daimeler-ek proposatzen duen sisteman, ardatzaren zimurtasunaren profil axialak neurtzen dira haren periferia osoan zehar; zehazki pieza $5^{\circ}$-tik $5^{\circ}$-ra biratzen da, eta haren profil axiala neurtzen da. Behin profil guztiak neurtu direlarik, neurtutako gainazala iragazi eta prozesatzen da.

Seewing-en arabera [11] macro-lead egitura duten gainazalek olatu itxurako profil periodikoak erakusten dituzte norabide axial zein periferikoan. Hala, 3 uhin sinusoidal harmonikoren gainezarpenaz osatzen den gainazal bat simulatzen du, anplitude eta uhin luzera jakin batzuekin (2. ek.). Parametro horiek askatzeko, simulatutako eta neurtutako gainazalen arteko optimizazioko best-fit erako algoritmo bat erabiltzen da Daimler-en metodoan.

$$
w(x, y)=\sum_{k=1}^{3} A_{k} * \cos \left(2 * \pi * k *\left(f_{x} * x+f_{y} * y\right)+\varphi_{k}\right)
$$

non $A_{k}$ simulatutako gainazalaren anplitudea, $\varphi_{k}$ fasea, eta $\mathrm{f}_{\mathrm{x}}$ eta $\mathrm{f}_{\mathrm{y}}$ norabide axial eta perimetraleko uhinen maiztasunak diren.

Hala $\mathrm{z}(\mathrm{x}, \mathrm{y})$ neurtutako gainazala bada eta $\mathrm{w}(\mathrm{x}, \mathrm{y})$ simulatuko den gainazala, ezezagunak diren parametroak minimo karratu bidezko optimizazioaren bidez askatuko dira ekuazio honi jarraikiz (3. ek.):

$$
(z-w)^{H} *(z-w) \rightarrow \min , A_{k}, f_{x}, f_{y}, \varphi_{k}
$$




\section{PROPOSATUTAKO NEURKETA METODOLOGIA}

Atal honetan, arteztutako topografian macro-lead erako testurak kuantifikatzeko metodologia baten garapena azalduko da, neurtutako gainazalaren Fourier-en transformazioan oinarrituko dena.

Metodologia honen bitartez, neurtutako gainazalak MBN 31 007-7 estandarraren arabera karakteriza daitezke. Hala, arteztutako piezen topografian agertzen diren patroi helikoidalen kuantifikazio objektibo bat egin ahalko da estandar internazionalei jarraituaz.

\subsection{Arteztutako gainazalen neurketa}

Metodologia balioztatzeko, diamantagailu estatiko berarekin baina aitzinapen abiadura ezberdinekin diamantatu den harri urratzaile (UNESA MA100IJ8V489) batekin arteztu dira altzairu tenplatuzko bi totxo lau. 1. taulan xehatzen dira diamantatze eta artezte saioak egiteko erabili diren parametroak pieza bakoitzaren kasurako, baina nabarmendu behar da diamantaketako aitzinapen abiadura soilik aldatu dela. Artezte operazioaren kasuan, parametro teknologiko berdinak erabili dira bi totxoak artezteko orduan: akaberako baldintzetan 3 pasaldi, eta txinparta akaberako pasaldirik gabe. Diamantaketako parametro teknologikoek patroi helikoidalen sorreran daukaten eragina nabarmentze aldera egin da parametroen aukeraketa.
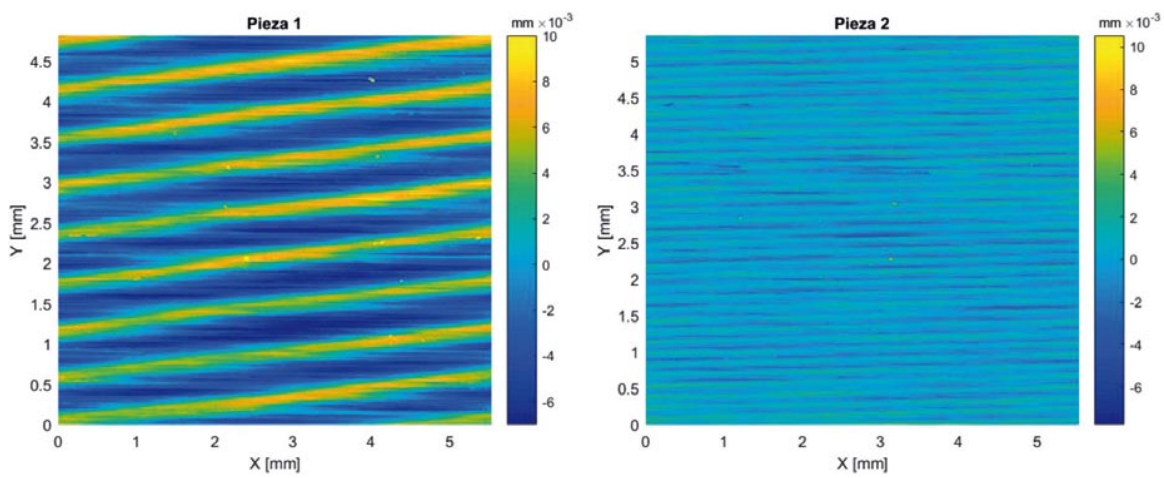

7. irudia. Proposatzen den neurketa metodologia balioztatzeko erabili diren neurtutako gainazalen topografia. a) arbastatze gainazala (1. pieza). b) akabera gainazala (2. pieza).

7. irudian ikus daitekeen moduan, diamantaketa aitzinapen ezberdinak erabiltzeak nabarmen alda dezake arteztutako piezen akabera gainazala. Gainera, neurtutako bi piezen kasuan begi hutsez nabari daiteke uhin itxurako gainazal bat sortzen dela. 
1. taula. Saioak egin diren gainazalen kasuan, erabilitako diamantaketa parametroak.

\begin{tabular}{lcc}
\hline \multicolumn{1}{c}{ Parametroak } & 1. pieza & 2. pieza \\
\hline$v_{d}[\mathrm{~mm} / \mathrm{min}]:$ diamantearen aitzinapen abiadura & 1200 & 300 \\
$v_{s}[\mathrm{~m} / \mathrm{s}]:$ harri urratzailearen abiadura periferikoa & 26 & 26 \\
$n_{s}[\mathrm{bira} / \mathrm{min}]:$ harri urratzailearen biraketa abiadura & 2000 & 2000 \\
$f_{d}[\mathrm{~mm} / \mathrm{bira}]:$ diamantearen aitzinapen abiadura & 0.6 & 0.15 \\
$U_{d}[-]:$ aitzinapen norabideko gainezarpen ratioa & 1 & 4 \\
$v_{w}[\mathrm{~mm} / \mathrm{min}]:$ mahaiaren abiadura & 7000 & 7000 \\
ae $(\mu \mathrm{m}]$ & 20 & 20 \\
Pasaldi kopurua [-]: & 3 & 3 \\
Txinparta pasaldi kopurua [-]: & 0 & 0 \\
\hline
\end{tabular}

Hala ere, gainazaleko uhin horien zigilatze ezaugarriak kuantifikatzea ez da zeregin erraza. Haatik, hurrengo atalean, gainazal horietan nabarmentzen diren uhin horien ezaugarriak zein diren kalkulatzen duen algoritmo matematiko baten garapena deskribatuko da.

\subsection{Gainazal sinusoidalen karakterizazioa. Fourierren transformatuaren bidezko gainazalen iragazketa}

\subsubsection{Gainazaleko maiztasun nagusiaren arabera}

Fourierren transformatua, transformazio matematiko bat da, zeinak denboraren edo espazioaren eremuko seinaleak maiztasunaren eremura pasatzen dituen. Funtzio horrek (4. ek.) hainbat aplikazio izan ditzake matematikan edo fisikan.

$$
F(u)=\int_{-\infty}^{\infty} f(x) * e^{-j 2 \pi u x} d x
$$

Hala, funtzio honen aplikazioetako bat espazioan periodikoak diren gainazalak iragaztea izan daiteke. Gainazalen neurketen kasuan, $\mathrm{z}(\mathrm{x}, \mathrm{y})$ eremuko gainazal tridimentsional baten aurrean gaude, beraren diskretizazioa $\mathrm{x}$ eta y norabideetan duena. Horregatik, seinale hori maiztasunen eremura pasatu ahal izateko 2D-ko Fourierren transformatua erabili beharko da (5. ek.).

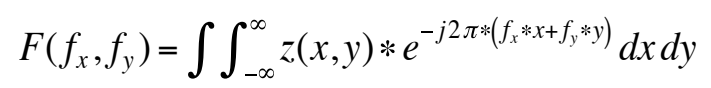

non $f_{x}$ eta $f_{y}$ maiztasun espazialak diren eta $F\left(f_{x}, f_{y}\right)$ eremuko matrize konplexu bat izango den. 
Neurtutako gainazalean (espazioaren eremuan $z(x, y))$ egitura periodikoak ageri direnean (8. irudia), 2 dimentsioko Fourierren transformatua aplikatu ondoren, $\mathrm{F}$ matrizearen moduluak $\left|F\left(f_{x}, f_{y}\right)\right|$ zenbait erpin erakutsiko ditu maiztasunen eremuan. Erpin horietako bakoitzak gainazaleko maiztasun nagusien informazioa gordetzen du. Zehazki, haien moduluak gainazaleko uhin horien sakoneraren inguruko informazioa gordetzen du. Maximo horien kokapenak, aldiz, gainazaleko testura periodiko bakoitzaren $\mathrm{x}$ eta y norabideetako uhin luzerak zein diren adierazten du, edota testura nagusiaren orientazioa zein den esan dezake (8. irudia).
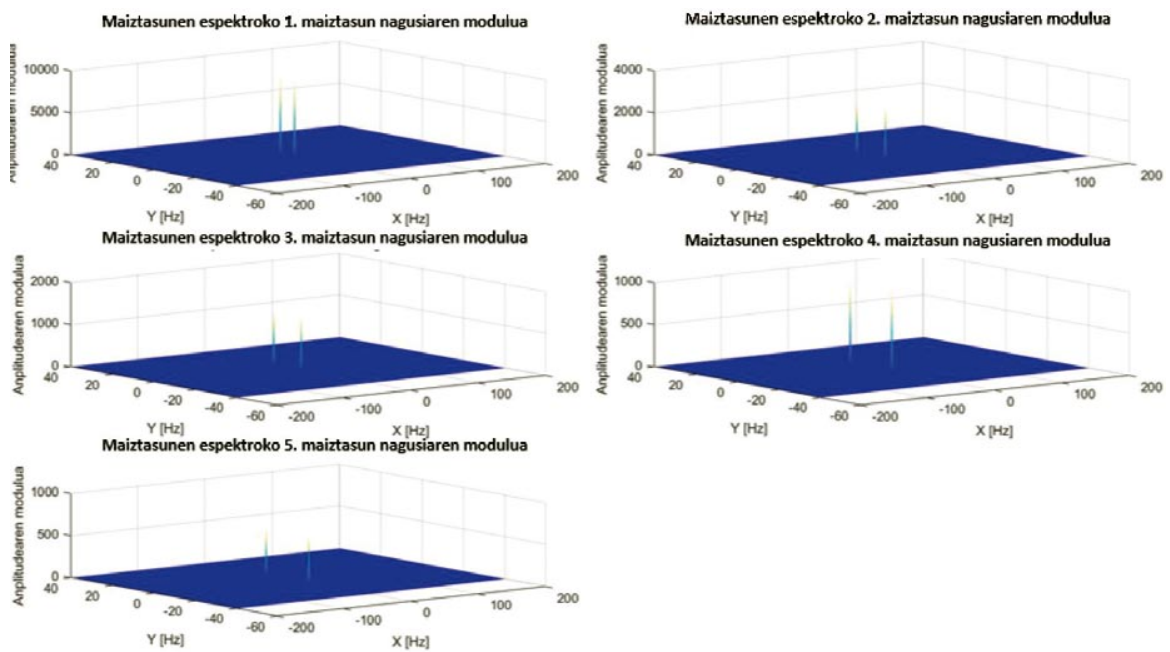

8. irudia. Neurtutako 1 piezaren gainazalaren 5 maiztasun nagusien detekzioa.

Hala, F matrizearen moduluak erakusten dituen 5 erpinik nabarmenak iragazi Fourierren alderantzizko transformatua aplikatuko zaio horietako bakoitzari, erpin bakoitzaren ezaugarriak espazioaren eremura pasatuaz (9. irudia) 

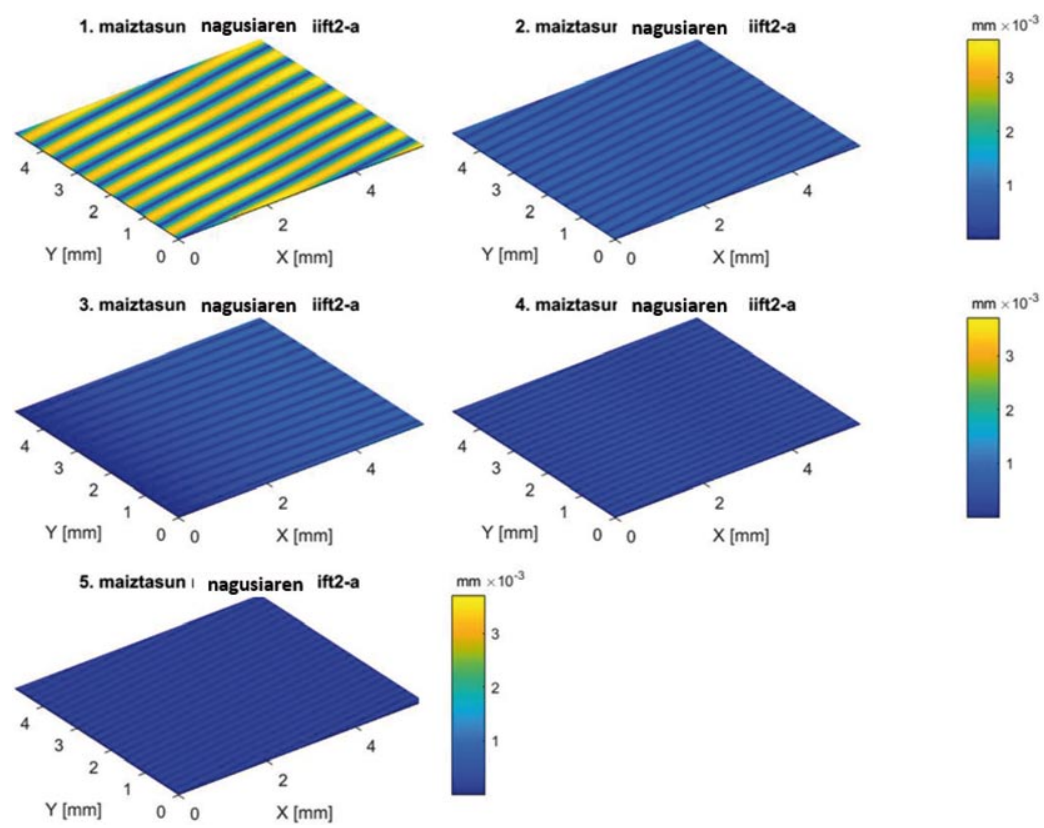

9. irudia. Neurtutako 1. piezaren gainazalaren 5 maiztasun nagusien gainazal singularrak: $\mathrm{W}(\mathrm{x}, \mathrm{y})$.

Behin 5 gainazal horiek espazioaren eremuan daudela, horien gainezarpenaren bitartez osatuko da neurtutako gainazalera ahalik eta egokien hurbilduko den topografiaren karakterizazioa (9. ek.). Hala, Matlab programazioko softwarearen laguntzaz optimizazio linealeko algoritmo bat aplikatuko zaie 5 maiztasun nagusiek definitzen duten gainazalen anplitudeen balioak askatuaz, neurtutako gainazalarekin minimizatuaz (10. ek.).

$$
W(x, y)=\sum_{i=1}^{5} a_{i} * i f f t 2\left(\left|F\left(f_{x i}, f_{y i}\right)\right|\right)
$$

non $a_{i}$ baita espazio eremuko $i$. maiztasun nagusia definitzen duen gainazalaren anplifikazio konstantea.

$$
\min (Z(x, y)-W(x, y)) \rightarrow a_{i}
$$

Adibide moduan, 10. irudian erakusten da 1. piezan neurtutako gainazalaren eta hurbildutako gainazalaren arteko konparazioa. Bost maiztasun nagusien uhinen gainezarpenak posible egiten du erabat sinusoidalak ez diren gainazaletarako hurbilketa, eta, hala, neurtutako piezaren antzeko gainazal bat lortzea. 

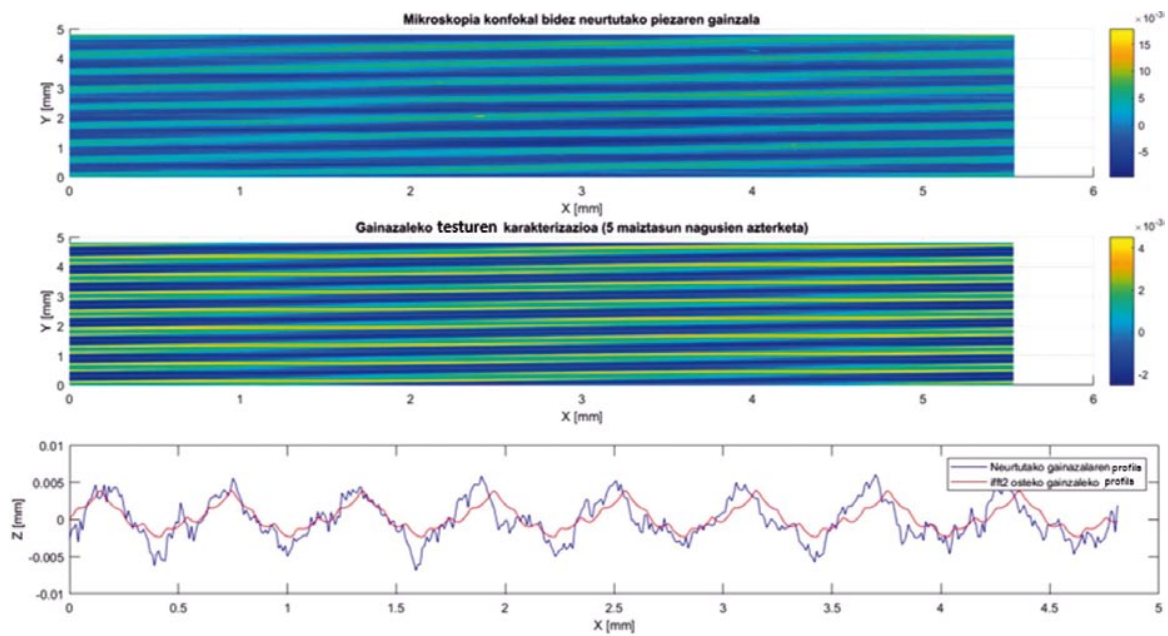

10. irudia. Neurtutako eta 5 maiztasun nagusien bitartez iragazitako gainazalen arteko konparazioa.

Gainazal hau MBN MBN 31 007-7 estandarraren arabera karakterizatze aldera, esan beharra dago maiztasunen eremuan moduluaren baliorik handiena erakusten duen erpinaren kokapena izango dela patroi helikoidalen norabidea eta maiztasuna ezartzen dituen parametroa (11. eta 12. ek.). $D t$ parametroa $W$ gainazalaren (9. ek.) maximoen eta minimoen arteko anplitudearekin bat etorriko da (13. ek.), eta $D F$ parametroa ondoz ondoko maximoen artean bildutako azalerak definituko du.

$$
\begin{gathered}
D_{\gamma}=\tan ^{-1}\left(\frac{f_{y}}{f_{x}}\right) \\
D P=\frac{1}{f_{x}} \\
D t=\max (W)-\min (W)
\end{gathered}
$$

2. taula. Neurtutako piezetako patroi helikoidalen ezaugarriak.

\begin{tabular}{cl}
\hline \multicolumn{1}{c}{ 1. pieza } & \multicolumn{1}{c}{ 2. pieza } \\
\hline$D_{\gamma}=-6.207^{\circ}$ & $D_{\gamma}=-1.538^{\circ}$ \\
$D t=5.947 \mu \mathrm{m}$ & $D t=0.855 \mu \mathrm{m}$ \\
$D P=0.603 \mathrm{~mm}$ & $D P=0.149 \mathrm{~mm}$ \\
$D F=141.293 \mu \mathrm{m}^{2}$ & $D F=4.984 \mu \mathrm{m}^{2}$ \\
\hline
\end{tabular}




\section{ONDORIOAK}

Artikulu honetan, era azkar eta objektibo batean gainazal arteztuetan agertu ohi diren patroi helikoidal makrogeometrikoak kuantitatiboki karakterizatzeko metodologia bat proposatu da, Fourierren transformatuaren bitartez gauzatzen dena.

Hain zuzen, arteztutako 2 gainazal lau neurtu dira haietan agertzen den patroi helikoidala karakterizatzeko asmoz. Nabarmendu daiteke gainazaletan marka periodiko edo errepikakorrak agertzen direnean gainazal horren 2 dimentsioko Fourierren transformatuak erpin batzuk agertuko dituela maiztasunen eremuan. Azaleratutako erpin horietako bakoitzak norabide, maiztasun eta anplitude jakin bateko uhin sinusoidalak irudikatzen ditu, eta horien gainezarpen printzipioa baliatuz neurtutako gainazalaren testura karakterizatu ahal izango da: zehazki, $D_{\gamma}, D t, D P$ eta $D F$ parametroak ebaluatuko dira.

Neurtutako gainazalean nabarmentzen den norabidea $\left(D_{\gamma}\right)$ eta uhin luzera $(D P)$ zehazteko orduan, nahikoa da anplitude maximoa erakusten duen maiztasunarekin geratzea. Aldiz, ildasken sakonera eta punpatze-sekzioa $(D F)$ zehazteko orduan, 5 maiztasun nagusien gainezarpenez osatzen den gainazala karakterizatuz zimurtasun-profilen geometria zehatzago bat lortzen da.

Nahiz eta metodo sistematiko hau homologatua ez egon, ikerkuntza munduan neurketen analisi konparatiboak egiteko orduan baliagarria gerta daiteke, diamantatze prozesuaren informazio esanguratsua ematen baitu. Esaterako, 2. taulako DP parametroari erreparatuz, ikus daiteke 1. taulan adierazten den diamantatze prozesuko aitzinapenarekin bat datorrela. Horrez gain, logikoa den moduan arbastatze parametroekin diamantatu den piezaren kasuan (1. pieza) $D_{\gamma}, D t$ eta $D F$ parametroek akaberako diamantaketa egin zaion piezak baino (2. pieza) balio handiagoak erakusten dituzte. Horrenbestez, metodologia honen garapenak diamantatze eta artezte prozesuetako parametro teknologikoek leadean zer eragin daukaten aztertzeko aukera emango du.

Aurrerago egingo diren saioei begira, interesgarria litzake mota ezberdinetako diamantagailuek uzten dituzten patroien nolakotasunak aztertzea. Batik bat diamantagailu birakarien kasuan $q_{d}$ parametroak daukan eragina aztertzea. Beste alde batetik, garrantzitsua gerta daiteke artezketa zilindrikoko parametroek leadean zer eragin daukaten aztertzea ere: esaterako, harriaren eta piezaren arteko biraketa abiaduren erlazioak edo txinparta denborak.

Analisi hau pieza lauen kasura mugatu den arren, antzeko metodologia gara daiteke erreboluziozko piezen kasurako, gainazalon periferiak neurtu eta forma zilindrikoa erauzteko iragazki bat aplikatuz gero $(F$-filter $)$. Etor- 
kizunera begira, pieza zilindrikoen macro leada karakterizatzeko neurketa metodologia azkar eta errepikakor bat garatzea izan daiteke markatu beharreko lan-ildo bat.

\section{BIBLIOGRAFIA}

[1] WEGENER, K., HOFFMEISTER, H. W., KARPUSCHEWSKI, B., KUSTER, F., HAHMANN, W. C., \& RABIEY, M. 2011. «Conditioning and monitoring of grinding wheels». CIRP Annals-Manufacturing Technology, 60(2), 757-777.

[2] JACKSON, M. J.; DAVIM, J. P. 2011. Machining with abrasivesç. New York: Springer, 2011.

[3] BAUMANN, M. 2013. How to measure lead in sealing technology?. Sealing Technology, vol. 2013, no 7, p. 8-12.

[4] ARNECKE, P. 2017. A measurement method for characterising micro lead on ground shaft surfaces. PhD Thesis. Technical University of Kaiserlauten.

[5] KUNDRÁK, J., GYÁNI, K., MARKOPOULOS, A. P., FELHŐ, C., \& DESZPOTH, I. 2016. Theoretical analysis of twist parameters in advanced grinding processes. Academic Journal of Manufacturing Engineering, vol. 14 , no 4.

[6] ISO 6194-1:2007. 2007. Rotary shaft lip-type seals incorporating elastomeric sealing elements. Part 1: Nominal dimensions and tolerances.

[7] Jenoptik twist measuring systems. 2014. Twist measurement in practice. URL: https://www.jenoptik.com/cms/products.nsf/0/2F860AF21E63168 8C1257D410033EA36/\$File/twist_parameters_en_10054993_08_2014. pdf?Open. Azken eguneratze data: 2014/08/27. 2018/05/17an kontsultatua.

[8] RMA OS-1-1. 2004. Oil Seal Technical Bulletin Shaft Finish Requirements for Rotary Lip Seals, Second Edition, Rubber Manufacturers Association.

[9] HORVE, L. 1996. Shaft seals for dynamic applications. CRC Press.

[10] HERTZSCH, A.; KRÖGER, K.; GROSSMANN, M. 2013. Optical twist measurement by scatterometry. Proceedings OPTO, p. 40-45.

[11] SEEWIG, J.; HERCKE, T. 2009. Lead characterisation by an objective evaluation method. Wear, vol. 266, no 5-6, p. 530-533. 